\title{
UAV Laser Scans Allow Detection of Morphological Changes in Tree Canopy
}

\author{
Martin Slavík*, Karel Kuželka®, Roman Modlinger, Ivana Tomášková and Peter Surový@ \\ Faculty of Forestry and Wood Sciences, Czech University of Life Sciences, Prague, Kamýcká 129, \\ 16500 Praha, Czech Republic; kuzelka@fld.czu.cz (K.K.); modlinger@fld.czu.cz (R.M.); \\ tomaskova@fld.czu.cz (I.T.); surovy@fld.czu.cz (P.S.) \\ * Correspondence: mslavik@fld.czu.cz; Tel.: +42-0731-315-937
}

Received: 14 October 2020; Accepted: 19 November 2020; Published: 21 November 2020

\begin{abstract}
High-resolution laser scans from unmanned aerial vehicles (UAV) provide a highly detailed description of tree structure at the level of fine branches. Apart from ultrahigh spatial resolution, unmanned aerial laser scanning (ULS) can also provide high temporal resolution due to its operability and flexibility during data acquisition. We examined the phenomenon of bending branches of dead trees during one year from ULS multi-temporal data. In a multi-temporal series of three ULS datasets, we detected a synchronized reversible change in the inclination angles of the branches of 43 dead trees in a stand of blue spruce (Picea pungens Engelm.). The observed phenomenon has important consequences for both tree physiology and forest remote sensing (RS). First, the inclination angle of branches plays a crucial role in solar radiation interception and thus influences the total photosynthetic gain. The ability of a tree to change the branch position has important ecophysiological consequences, including better competitiveness across the site. Branch shifting in dead trees could be regarded as evidence of functional mycorrhizal interconnections via roots between live and dead trees. Second, we show that the detected movement results in a significant change in several point cloud metrics often utilized for deriving forest inventory parameters, both in the area-based approach (ABA) and individual tree detection approaches, which can affect the prediction of forest variables. To help quantify its impact, we used point cloud metrics of automatically segmented individual trees to build a generalized linear model to classify trees with and without the observed morphological changes. The model was applied to a validation set and correctly identified $86 \%$ of trees that displayed branch movement, as recorded by a human observer. The ULS allows for the study of this phenomenon across large areas, not only at individual tree levels.
\end{abstract}

Keywords: ULS; LiDAR; forestry; canopy changes; branch bending; change detection

\section{Introduction}

Long-term planning, as well as operative decisions in managing forest properties, rely on accurate and up-to-date information. Remote sensing has proven to be a viable method for the fast and accurate acquisition of data describing different aspects of forest conditions for decision-making [1]. Recent remote sensing approaches to evaluating forest inventory parameters are mostly based on three-dimensional (3D) structural information derived from digital aerial photogrammetry (DAP) or aerial laser scanning (ALS). To quantify many important forest inventory parameters, such as heights, basal areas, and volumes, an ABA is often applied to three-dimensional point clouds produced using DAP or ALS [2-4]. Using ABA, entire homogenous areal units, such as forest stands or grid cells, are characterized by a single representative value of a given parameter, which is based on various metrics describing the 3D structure of point clouds, with an emphasis on the vertical component of the structure. However, intraseasonal changes in tree structure, such as periodic movement of plant 
organs, can significantly change values of selected point cloud metrics, which would in turn notably affect the estimated inventory parameters based on the relation of tree crown size and diameter at breast height (DBH) [5].

Plant movement has been detected and described by several authors since the nineteenth century [6]. Biological oscillations are driven by more than 20 genes, including TOC1, LHY, and CCA1. The LHY and CCA1 genes stimulate the construction of light harvesting antennas of the photosynthetic apparatus, and concentrations of $\mathrm{TOC} 1$ gene products do not begin to increase until the night [7]. The main driving factor is the light captured by photoreceptors. They are responsible for nyctinastic movements, start of flowering, and photomorphogenesis. Differences in osmotic potentials and photoperiodism are the cause of circadian movements, and they are typical for leaves, flowers, and branches. Of all stem and branching properties, branch angle has the highest heritability and is under strong genetic control [8]. Nevertheless, it does change under different environmental conditions [9]. Morphological changes in silver birch (Betula pendula Roth) tree crowns during circadian cycles were detected in terrestrial laser scanning (TLS) data in Finland and Austria, with the biggest changes occurring at sunrise and sunset [10]. A second study [11] was aimed at the detection of circadian movements of 18 selected tree species individuals. In both highly-cited studies $[10,11]$, the TLS method was used for data acquisition, and both author collectives concluded that the method was time-demanding. In contrast to TLS, the ULS data acquisition provides lower point cloud density matched with high time efficiency [12-15]. A yearlong investigation of the branch inclination angles using TLS was not performed on forest trees. Similarly, all investigations of crown morphology changes with respect to environmental factors were done exclusively on living trees.

LiDAR (light detection and ranging) technology is based on the active sensing of laser beams and it provides a practical option to measure tree heights and other important tree parameters [16,17]. Relative to other modern remote sensing technologies, LiDAR provides the opportunity to assess detailed characteristics of a single individual tree and its components [18,19]. The first research focused on LiDAR observations of trees was described by [20]. The authors tried to delineate tree stem profiles using harvested trees mounted in a vertical position observed by a LiDAR system mounted on a crane arm; the data were then compared with traditional tape measurements.

The LiDAR laser scanning method for forestry data acquisition can be used at several levels depending on the level of detail (point density) and time consumption per square unit with respect to possible accuracy and precision. The first LiDAR method commonly used in forestry research practice was the ALS, which allowed for observing large areas at regional scales. Individual tree detection based on forest structure canopy profiles in ALS data using returned echoes emitted from a pulse laser scanning device has been described by [21]. Terrestrial laser scanning (TLS) was later used to provide ultra-high-density point clouds at the tree level; it can very precisely represent tree architecture, thus allowing for the definition of specific morphological trends [22]. Two studies have demonstrated the effectiveness of TLS for estimating aboveground biomass (AGB) and quantitative structural models (QSMs) at the individual tree level with regard to high possibility of tree morphology reconstruction at the peripheral tree branch level [23,24].

The ULS method combines the relatively high point density and accuracy of TLS with the time efficiency and possibility of recording several returns in canopy from ALS; however, the ULS method cannot achieve such high accuracy and point density as TLS. Thanks to multi-angle scanning, the ULS data can, with high detail, represent individual trees and their components with accuracy approaching $10 \mathrm{~mm}$ at the forest, stand, or sub-compartment scales. The first study aimed at UAV LiDAR data acquisition and evaluation was presented by [25], where the authors used a combination of instruments, Ibeo Lux and a Sick LMS151. The mentioned study presented the pole method for tree detection. The author collective of [26] presents the early development of a low-cost UAV LiDAR TerraLuma, where they reached a point density of 62 points $\mathrm{m}^{2}$. The same unmanned aerial system (UAS) used for this study is suitable for forestry application. Based on reference data from TLS measurements from several stands in sampled plots, studies have demonstrated the high potential of the ULS VUX-SYS 
(RIEGL Laser Measurement System GmbH, Horn, Austria) setup for forestry data acquisition [12,13]. The point densities in the lower stem portions were not as high as those produced using TLS methods, but they would be quite sufficient for the derivation of forest inventory values, such as diameter at breast height $(\mathrm{DBH})$, or for estimating AGB using ULS data. Moreover, both studies suggested the possibility of using ULS data to produce high-resolution digital terrain models (DTM) and canopy height models (CHM).

The utilization of a CHM calculated from a DTM and a digital surface model (DSM) derived from photogrammetry data for forest inventory purposes focused on tree delineation-in particular, individual tree height and crown projection derivations-in the ArcGIS environment using the inverse watershed segmentation (IWS) method has been described with the overall workflow [27]. The photogrammetry RS methods are based on a developed scale-invariant feature transform algorithm [28]. One study [15] described and evaluated several methods for tree detection, including IWS, individual tree segmentation (ITS), and point cloud segmentation (PCS), and ULS has also been used for individual tree detection [25]. The advantage of low cost and feasible multi-temporal data acquisition for the derivation of DTM and individual tree change detection based on CHM will also be used for estimation of carbon stock, describing the carbon dynamics [29], and for describing the forest vertical structure [30] from the International Space Station (ISS) module, NASA's Global Ecosystem Dynamics Investigation (GEDI) data. The forest ecosystems are a carbon source, yet forests have great potential to capture carbon dioxide from the atmosphere [31]. The carbon changes-that is, the carbon losses-were mapped at large scales using LiDAR technology across tropical forests by [32] from time series data based on cell analysis by random forest classification [33].

This study describes the detected movements of dead tree branches and their detection in forest stands using individual tree metrics for the derivation of a generalized linear model (GLM) on two datasets, one for GLM derivation and the second for data validation.

\section{Materials and Methods}

\subsection{Research Area}

The forest stand is located in the northern region of the Czech Republic, near the village Moldava $\left(50^{\circ} 41^{\prime} 5.619^{\prime \prime} \mathrm{N}, 13^{\circ} 38^{\prime} 38.500^{\prime \prime} \mathrm{E}\right)$ in the Ore Mountains (Figure 1), with orientation to the south and $35 \mathrm{~m}$ elevation gain (from $832 \mathrm{~m}$ AMSL to $867 \mathrm{~m}$ AMSL). The research plot was situated in an approximately 2.2 ha area of an even-aged stand of 460 blue spruce (Picea pungens Englem.) trees with mean height $9.12 \mathrm{~m}$ (range of height from 3.13 to $12.61 \mathrm{~m}$ ) and 1.61 height standard deviation. This species was introduced to the mountainous regions as a substitute for the dying forest stands during the 1970s [34], mainly because of the pollution emissions from the coal-powered power plants surrounding the Ore Mountains on both the Czech and German sides of the range. The stand has since been infested by bud blight Gemmamyces piceae (Brothw.) Casagr., which has caused the death of 43 individuals on the plot. The impacts of these pathogens across the Ore Mountains have been described by [35]. 


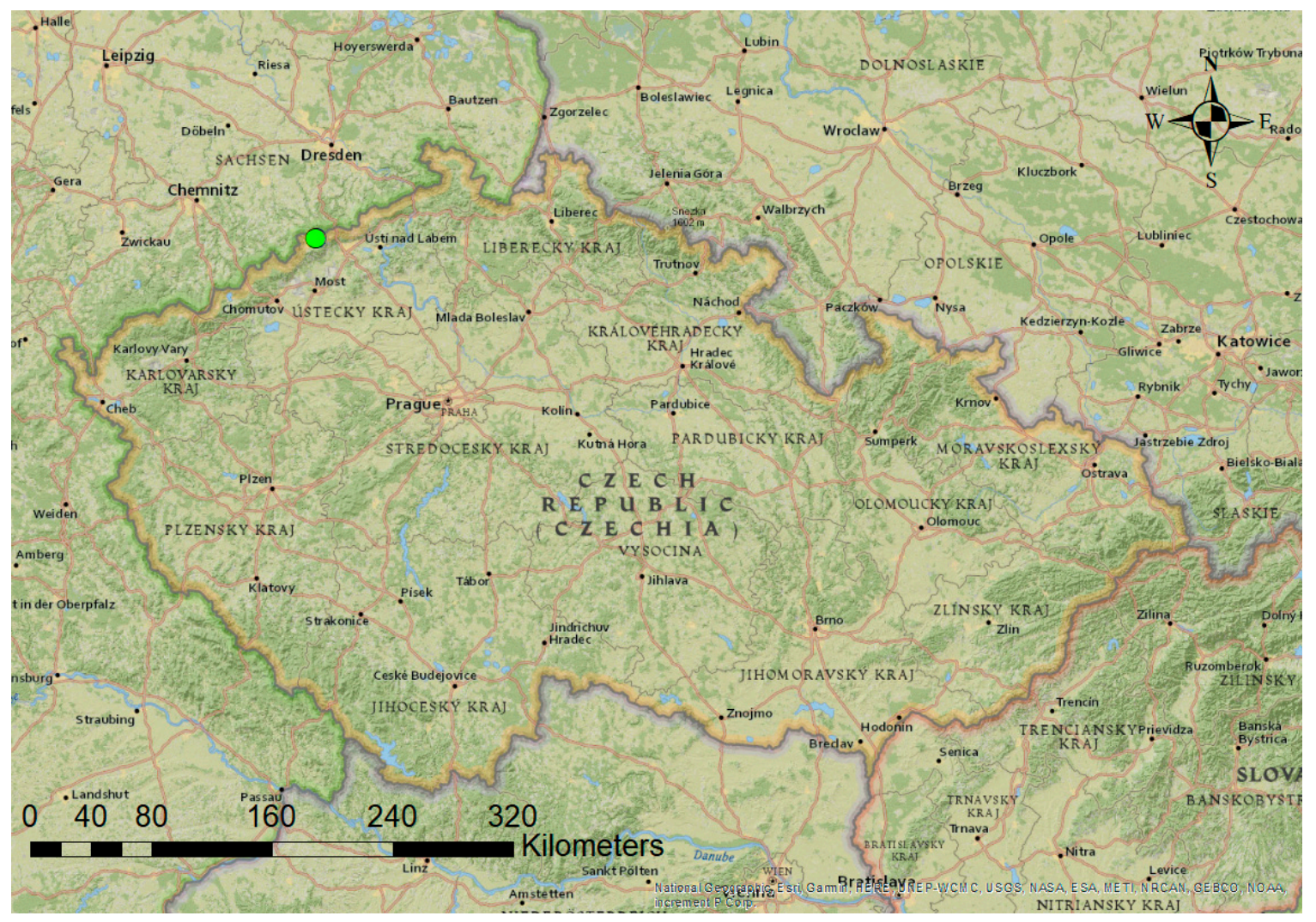

Figure 1. Location of the research plot in the northern region of the Czech Republic. The plot is marked with green point.

\subsection{Data Acquisition}

We used the UAS VUX-SYS (RIEGL Laser Measurement System GmbH, Horn, Austria) setup for UAV-borne data acquisition consisting of the UAV RiCOPTER, the VUX-1UAV laser scanner, and the AP-20 inertial measurement unit (IMU). RiCOPTER is an eight-propeller UAV with a carbon body [36], with detailed information given in Table 1. VUX-1UAV is a high-speed infrared laser scanner using online waveform processing with a maximum frequency of $550 \mathrm{MHz}$ and $330^{\circ} \mathrm{FOV}$ (field of view); this configuration provides a beam range up to $300 \mathrm{~m}$. The AP-20, made by APPLANIX (Applanix, Richmond Hill, ON, Canada), is a multipurpose IMU focused on reaching high accuracy and precision of acquired data in the form of 3D digital point clouds. This component is important in trajectory post-processing with regard to trajectory-based solutions of data derivation and co-registration of single scans acquired during the flight.

Table 1. Detailed information about VUX-SYS provided by [36].

\begin{tabular}{cc}
\hline RiCOPTER & Characteristics \\
\hline Total weight & $25 \mathrm{~kg}$ \\
Sensors (VUX-1UAV + cameras) & $3.5 \mathrm{~kg}$ \\
Batteries (Li-Pol 29.4V 12,500 mAh) & $7.5 \mathrm{~kg}$ \\
Maximum flight time & $28 \mathrm{~min}$ \\
Maximum horizontal speed & $14 \mathrm{~m} \cdot \mathrm{s}^{-1}$ \\
Maximum ascending speed & $5 \mathrm{~m} \cdot \mathrm{s}^{-1}$ \\
Maximum descending speed & $2 \mathrm{~m} \cdot \mathrm{s}^{-1}$ \\
\hline
\end{tabular}

UAS data acquisition (Figure 2) was performed during three independent campaigns (7 May, 23 July, and 10 November, 2019) with the use of the UAS VUX-SYS setup. All three flights were 
flown automatically, following an identical predefined trajectory. The trajectory was planned and the flights performed using the UgCS (Universal Ground Control Station) mission planning software (SPH Engineering, Riga, Latvia). The trajectory followed a perpendicular zigzag pattern consisting of parallel lines with 50-m spacing. The zigzag pattern with overlaps between individual scan lines was used for reaching high point density, mainly for highly detailed individual tree point clouds. The data were acquired only during the uniform straight-line motion of the UAV; for stops and turns in the trajectory vertices, data acquisition was discontinued. The UgCS software contains DTM, which allowed us to fly the vehicle at a constant aboveground height, which enabled the acquisition of uniform point densities throughout the study site.

The VUX-1UAV laser scanner was set to its maximum pulse frequency of $550 \mathrm{kHz}$ with a registration of 200 scanning lines per second. The flight was performed at a constant altitude of $90 \mathrm{~m}$ aboveground, with a constant ground speed of $6 \mathrm{~m} \cdot \mathrm{s}^{-1}$. This setup reached an average point density of 200 points $\mathrm{m}^{2}$ for each scanning line. Due to the overlap of individual scanning lines, the final point density was around 2000 points $\mathrm{m}^{2}$.

During mission planning, we accounted for UAV weather limitations with a maximum wind speed of $10 \mathrm{~m} / \mathrm{s}$ and a temperature interval from -10 to $+40{ }^{\circ} \mathrm{C}$ [36]. We also observed all the national law restrictions, summarized in [37], of which the most important are a maximum flight altitude $300 \mathrm{~m}$ aboveground, visual line of site between pilot and UAV, availability of the air space (controlled on web portal of Air Navigation Services of the Czech Republic), and minimum distance from people and buildings.

Red-green-blue (RGB) imagery of the research area was acquired with a DJI Phantom 4 Pro (DJI, Shenzhen, China) during a planned automatic flight using the PrecisionFlight mobile phone application. The aboveground flight altitude was $100 \mathrm{~m}$, the maximum speed was set to $6 \mathrm{~m} \cdot \mathrm{s}^{-1}$, and front and side overlap was $85 \%$.

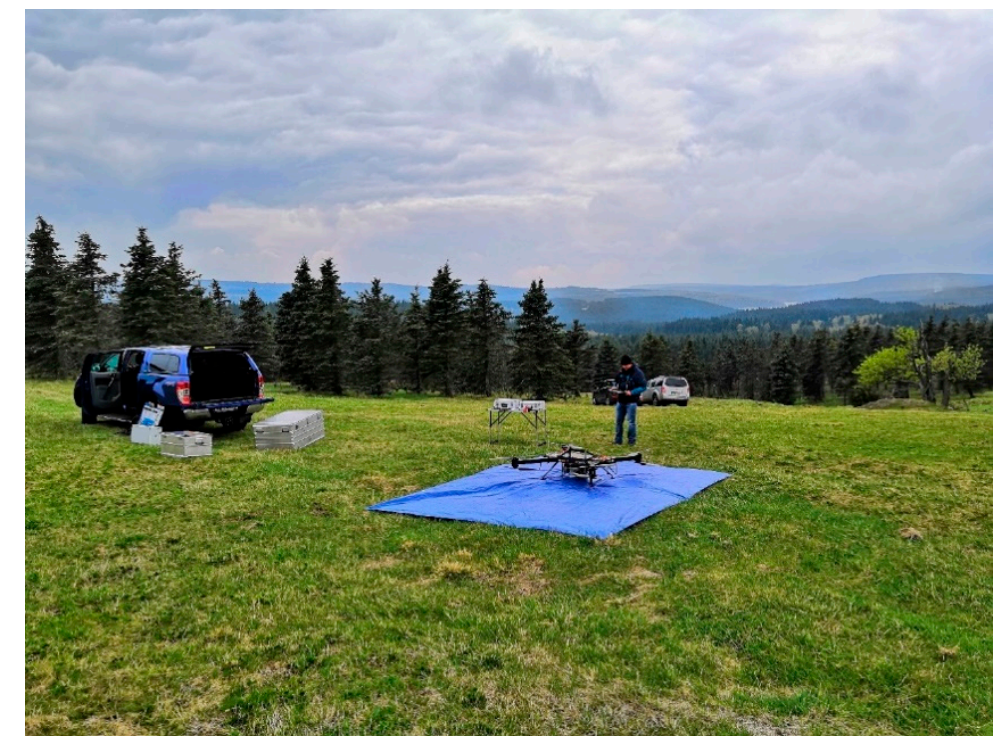

Figure 2. The UAS VUX-SYS setup and pilot before takeoff during the spring data acquisition (7 May 2019).

\subsection{Data Processing}

Prior to the initial point cloud creation, we needed to create trajectory calculations. Raw trajectory is not accurate and it does not provide sufficient accuracy for the individual tree level analyses. To develop the appropriate trajectories, we used reference station (RS) post-processing kinematics (PPK) with the virtual BS from Trimble VRS Now, which entered the calculation process as data in RINEX format. With regard to forward and backward calculations not exceeding the difference of $3 \mathrm{~cm}$ standard deviation, the RS PPK correction was applied in the environment of software POSPac 
MMS 8.1 (Applanix: a Trimble company, Richmond Hill, ON, Canada). The result of PPK trajectory calculations was smoothed best estimate of trajectory (SBET). Based on the recalculated SBET trajectory, the initial point cloud was derived from the raw data of VUX-1UAV in the environment of RiPROCESS (RIEGL Laser Measurement System Gmbh, Horn, Austria). The accuracy of the whole point cloud was improved by module RiPRECISSION included in the RiPROCES software. The RiPRECISSION module improved the co-registration of single scans according to the straight parts of the trajectory, mainly along the $Z$ axis. RiPROCESS also enables basic point cloud classification, which was sufficient for this study. Points were assigned to one of three classes; the first class contained isolated points represented mainly by noise based on the minimum number of neighbors within a defined distance, and all other points were classified as vegetation or ground points. Not all points lying on the ground were classified as ground points, but this basic approximation of ground in the point cloud helped to improve individual tree detection.

RGB geotagged imagery was processed in Agisoft MetaShape 1.6 (Agisoft LLS, St. Petersburg, Russia) following the standard workflow of SfM (structure from motion) scene reconstruction (e.g., as described in [38,39]). Subsequently, we derived an orthomosaic of the whole research area. Segmentation of individual trees in CHM derived from ULS point cloud was performed in ArcGIS 10.6.1 (ESRI, Redlands, CA, USA) with the use of 3D Sample Tools toolbox. Individual tree tops were detected as local maxima of CHM, and crowns of individual trees were segmented using the IWS algorithm described by [27]. The tree positions were assigned a unique ID for individual trees, which were verified on the ground to avoid missing trees. For each individual tree, IWS was used to identify the points associated with the tree, and we could then produce crown segmentation for the tree.

\subsection{Field Data Collection}

All detected trees were marked in the forest stand by their assigned IDs, which allowed for easy field recognition of each individual tree for human observer-based canopy change detection. The true orthophoto was overlaid with the point layer with IDs of all individual trees, which facilitated orientation and highly limited the possibility of misidentification of the trees in the stand. The health status of each individual tree was evaluated based on the defoliation rate, as described by [40]. Defoliation rate was determined as an indicator of health status according to the grading system used for ICP (International Co-operate Program)-forest monitoring, based on the individual evaluating the defoliation on a scale from 0 to $100 \%$, with $5 \%$ increments. Each tree was evaluated from four main cardinal directions by two evaluators, who were trained for such types of evaluation. These data were later used for evaluation of health status of bending branch trees.

\subsection{Evaluation}

The next step was to verify whether bending tree branch changes could be quantified by a set of canopy metrics and automatically identified. Simultaneously, this step allowed identification of canopy metrics that were significantly affected by the tree habitus (outer look) change. For this purpose, the research area was divided into two parts of equal size. Half of the total 408 trees in the research plot, i.e., 204 trees, served as training data for the model; the other 204 trees were kept retained for validation. The training set and validation sets contained 14 and 29 trees, respectively, with detected habitus changes.

The IWS polygons representing horizontal crown projections of individual trees identified in the spring point clouds were used as clip masks to clip points belonging to individual trees from spring and summer LiDAR point clouds. As a result, a time series of two point cloud representations (spring and summer) with identical spatial extents were available for each of the 408 segmented trees. Vertical $(Z)$ coordinates were normalized so that the normalized height of points in each tree was between 0 and 1. Each tree was sliced into 10 uniform vertical layers, so that layer 1 contained points 
with normalized heights between 0 and 0.1 , and so forth. For each layer, a convex hull of vertical projection of corresponding points was defined and the area of the convex hull was calculated.

For each tree, we quantified eighteen point cloud metrics for both spring and summer point clouds: A1 consecutive through A9 denote areas of convex hulls in layers 1 through 9, respectively; Q1 consecutive through Q9 denote 0.1 through 0.9 quantiles of the normalized heights, respectively. The index describing the spring to summer change in each metric was defined as the summer value divided by the spring value (i.e., $\mathrm{A} 1_{\text {change }}=\mathrm{A} 1_{\text {summer }} / \mathrm{A} 1_{\text {spring }}$ ). Index values higher than 1 expressed an increase in the metric, while values lower than 1 demonstrated a decrease in the metric value.

The temporal changes in crown metrics were used as predictors in a generalized linear model to explain the presence or absence of habitus change (the response variable). We used the additive form of the model without interactions, and according to the nature of the response variable, we chose a binomial error distribution model by the stepwise regression method with regard to AIC (Akaike information criterion) value [41].

\section{Results}

\subsection{The Detected Trees}

From the three flights were derived three point clouds with an average of 2082 points $\mathrm{m}^{2}$ for the first flight, 1525 points per $\mathrm{m}^{2}$ for the second flight, and 1582 points per $\mathrm{m}^{2}$ for the third flight. A total of 460 individual trees were automatically identified, which correlated with the 460 trees in the forest stand-a detection rate of $100 \%$ with 0 omitted trees. Figure 3 shows the derived orthophoto from 179 geotagged images with ground sampled distance $2.81 \mathrm{~cm} \cdot$ pixel. Not all trees were properly delineated, as represented by inaccurate automatic creations of horizontal crown projections represented by their polygons in ArcGIS 10.6.1 (ESRI, Redlands, CA, USA). The final dataset was comprised of 408 trees with completely delineated crowns.

Detected individual tree positions are shown in Figure 3; there is an obvious visible space shift caused by different accuracies of the photogrammetry data (geotagged images from DJI Phantom 4 Pro) contrary to the high accuracy of ULS (derived using trajectory of PPK from VRS Now BS).

Figure 4 highlights an example of height difference rasters and demonstrates the difference between two selected trees. The estimated tree top is marked with an individual Id, detected as a local height maximum and used as a tree position. Tree 273 shows a marked difference in its crown configuration compared to the neighboring tree 265 between spring and summer (Figure 4a), but there is no significant difference between the two trees between spring and autumn (Figure $4 \mathrm{~b}$ ). The red color surrounding tree 273 shows the negative change in height raster values representing the bent branches.

Figure 5 depicts two neighboring trees based on the point clouds derived from the three flights; the tree on the right clearly has its branches turned down during the summer (Figure $5 b$ ), but the tree on the left displays no significant changes in branch angles over time. In Figure $5 \mathrm{~d}$, a noticeable height increment is obvious in the tree on the left (265), compared to the tree on the right (tree 273, a dead tree), where no visible height increment was evident. The reversible bending of the branches of the dead tree followed by the recovery close to the initial position is also evident. 


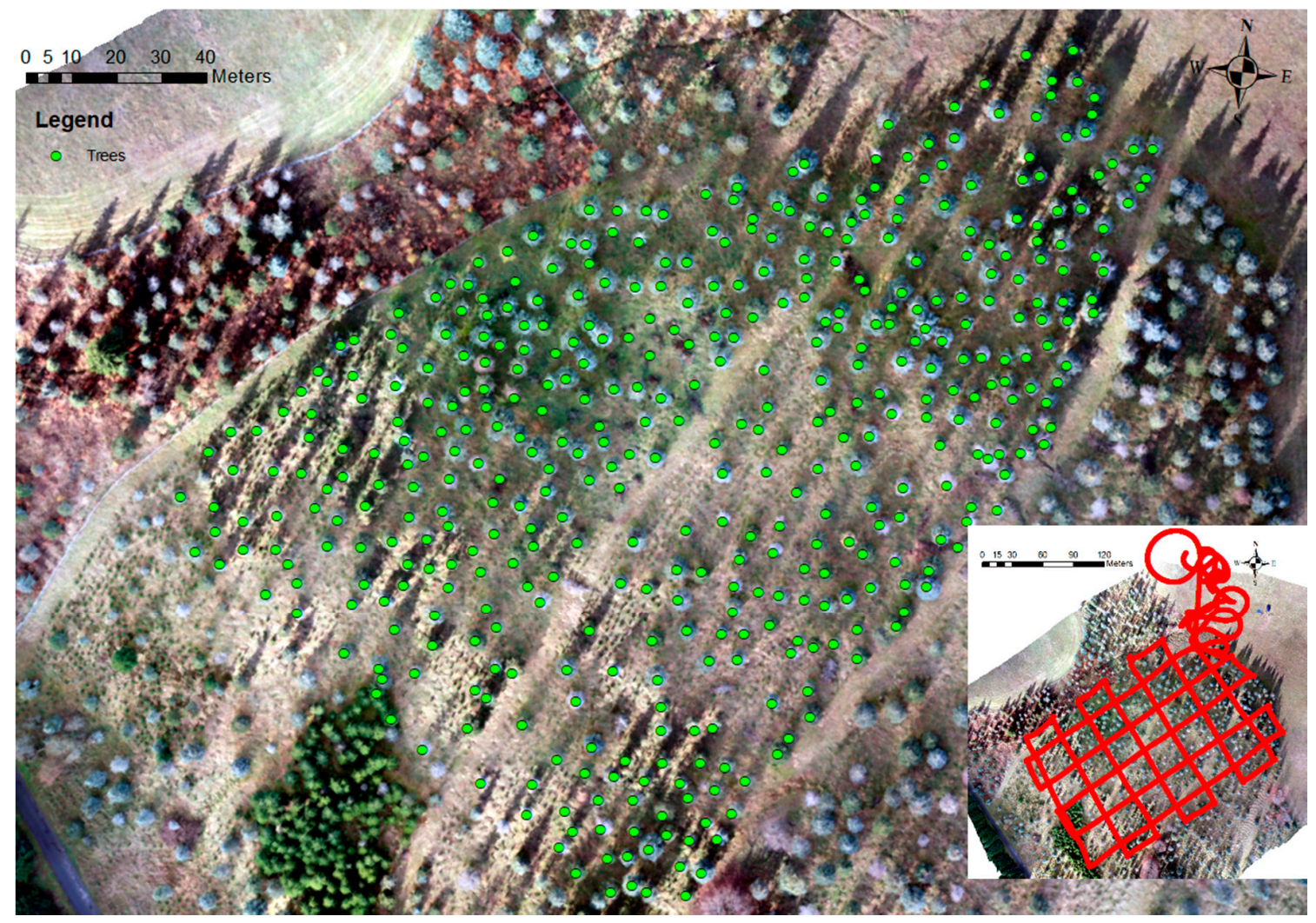

Figure 3. Detected positions of all trees derived from ULS point cloud in the stand overlapping the high-resolution orthophoto. The orthophoto mainly helped with the ground survey for better orientation during field data acquisition and for human observer tree detection verification. The spatial shift is mainly the result of using recalculated trajectory based on PPK from ULS and the aerial imagery from aerial photogrammetry was not corrected. In the bottom right corner is an example of a used trajectory.

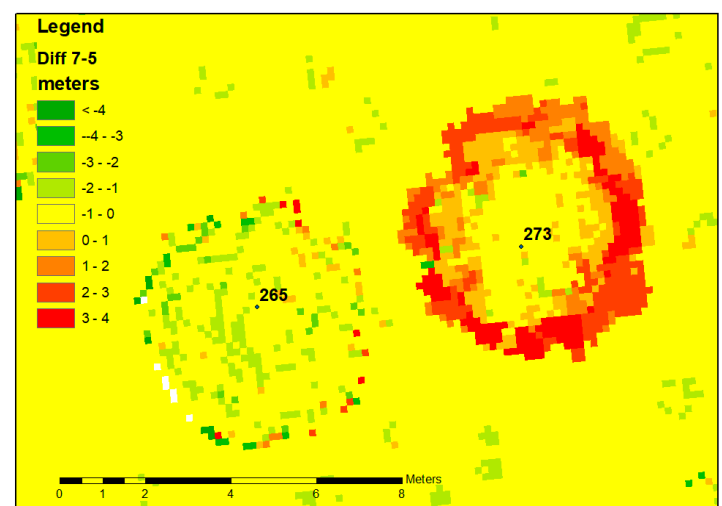

(a)

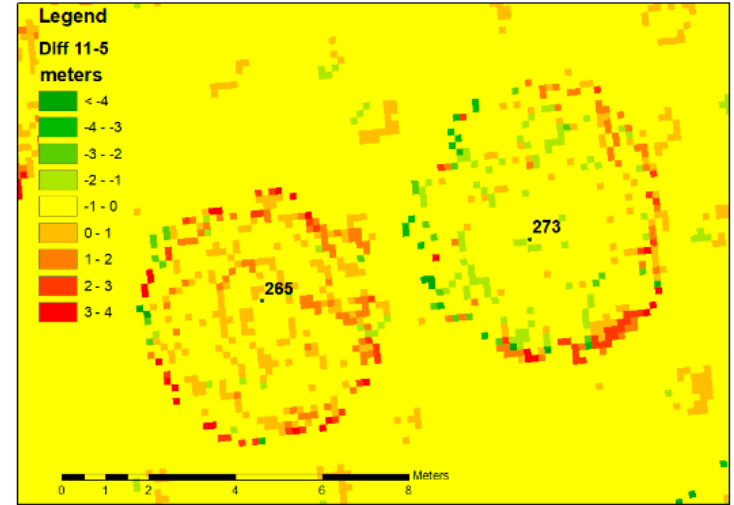

(b)

Figure 4. Comparison of two selected tree heights (maximum height value in raster cell from 3D point cloud) displaying raster of $10 \mathrm{~cm}$.pixel differences of two flights where tree 265 was not detected to have bending branches and tree 273 was detected to have bending branches: (a) Difference between summer and spring flight; raster values around tree 273 are red cells with positive values showing the difference in crown structure (e.g., bent branches); (b) Difference between spring and autumn flights; cell values around tree 273 show no difference, as the branches have returned to their spring positions. 


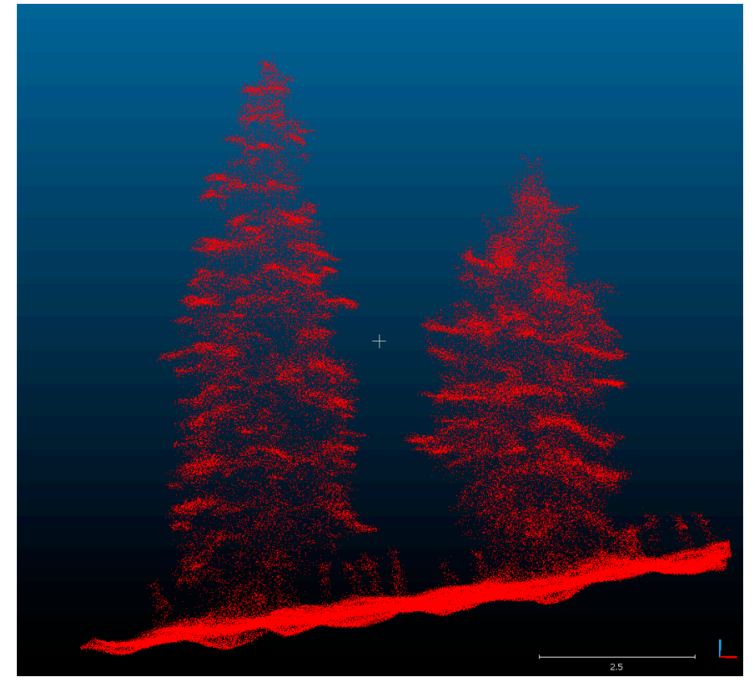

(a)

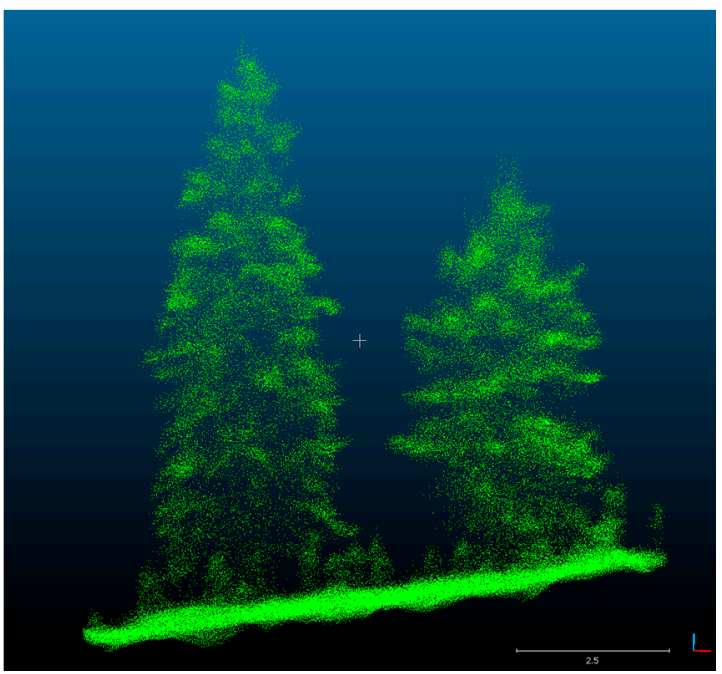

(c)

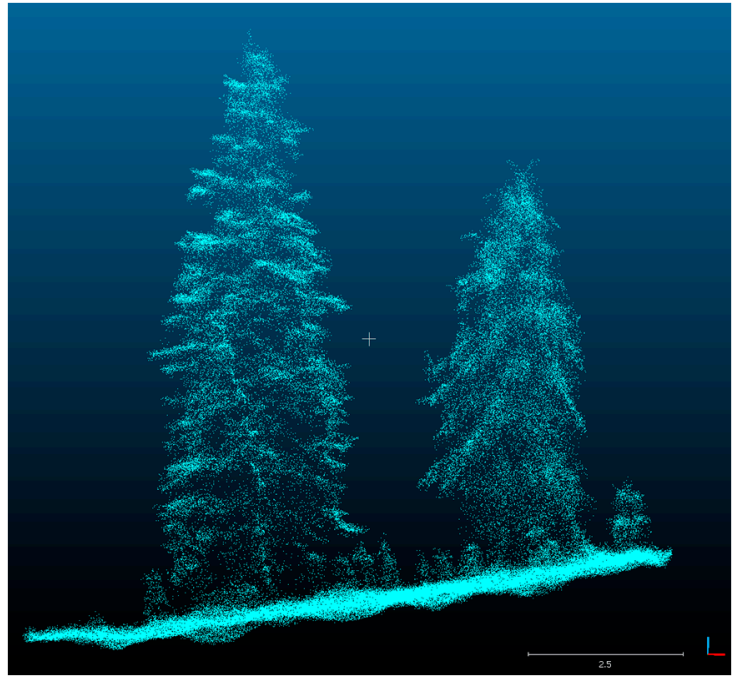

(b)

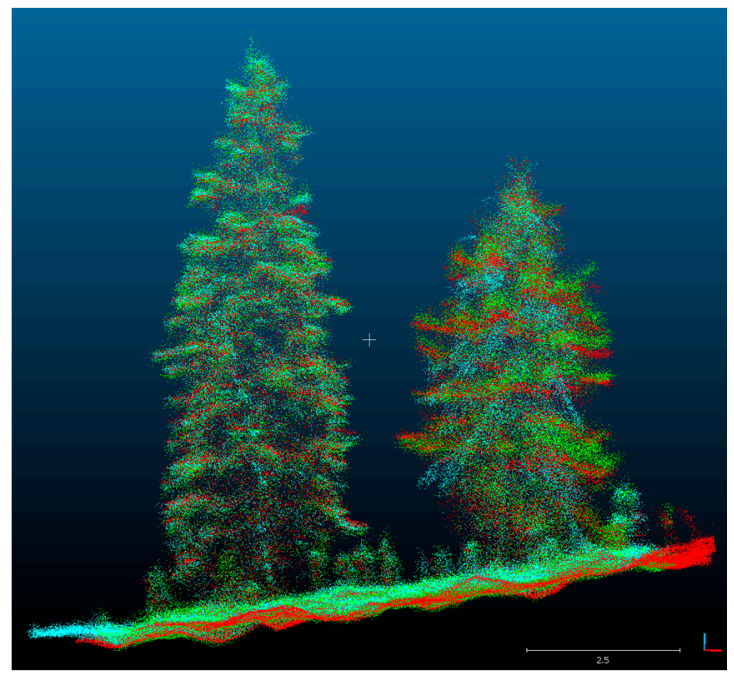

(d)

Figure 5. Examples of individual tree point clouds for tree 265 (on the left) and tree 273 (on the right). For this example, we used the same two trees as described in Figure 3. The individual plates show the point clouds for the two trees: (a) spring flight with tree 273 with branches straight; (b) summer flight with tree 273 branches bent; (c) autumn flight with tree 273 with branches in the original position; (d) all three point clouds overlapped.

Figure 6 displays boxplot distributions of calculated areas (Figure 6a) and quantiles (Figure 6b) for trees with no evidence of bending branches (yellow) and dead trees with bending branches (green). For the derivation of the GLM, we used only the area indices (Figure 6a). 


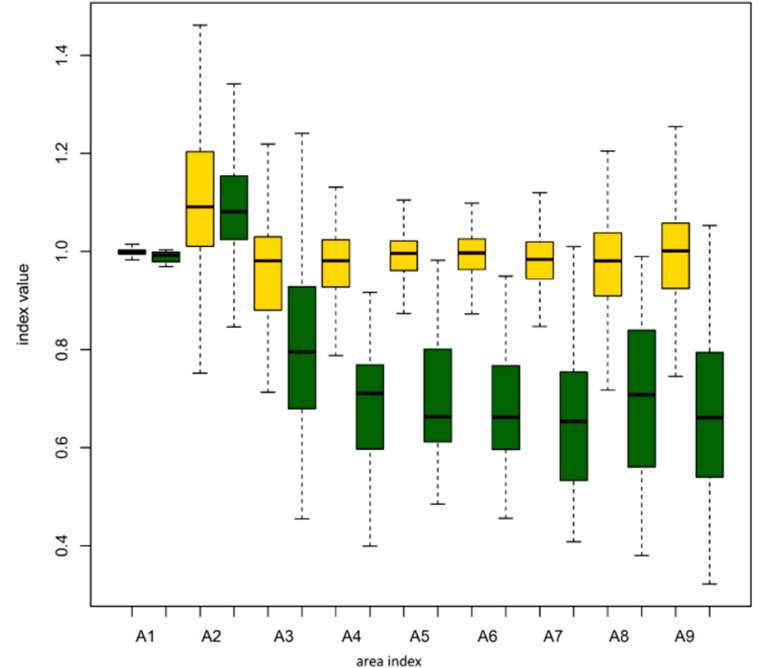

(a)

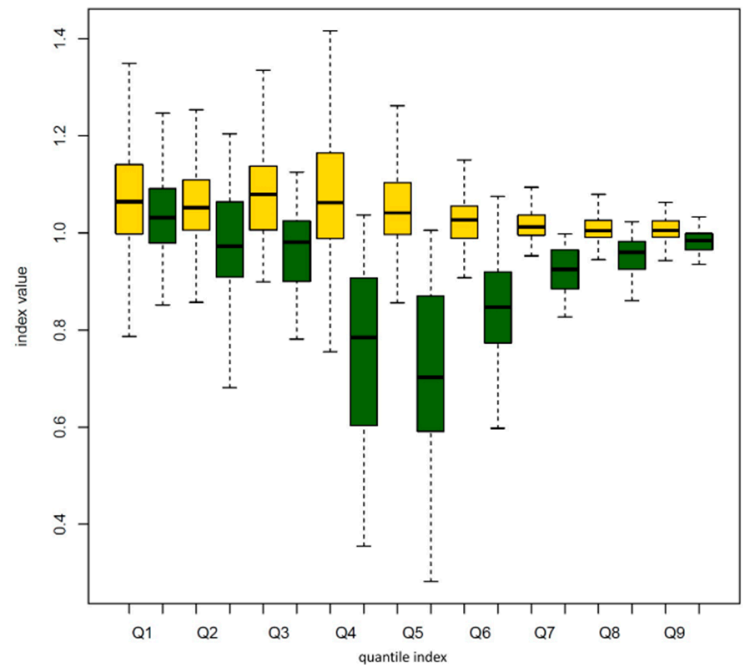

(b)

Figure 6. Boxplots for calculated areas (a) and quantiles (b) along tree lengths; yellow bars represent trees with no bending branches, and green bars represent dead trees with evidence of bending branches. On horizontal axis are described the names of used metrics and on the vertical axis are index values.

\subsection{Automatic Identification of Trees with Habitus Change}

Of the nine predictors representing the temporal changes in canopy metrics, five showed a significant difference, including A1, A2, A5, A6, and A9 (Table 2). The most significant predictor was the area change in the lowest layer (A1), where the increase in layer area was the result of the bending branches from the upper layer. However, in some trees of the validation set, the area change could not be detected due to the presence of objects, such as stumps or deadwood, in the area of the tree, and the model failed to identify such trees.

Table 2. The derived GLM from nine calculated canopy metrics for individual trees.

\begin{tabular}{ccccc}
\hline & Estimate & SE & tStat & $p$-Value \\
\hline Intercept & 32.884 & 22.659 & 1.451 & 0.1467 \\
A1 & 43.728 & 30.725 & 1.423 & 0.1547 \\
A2 & 6.350 & 4.130 & 1.538 & 0.1241 \\
A5 & -53.701 & 26.340 & -2.039 & 0.0415 \\
A6 & -28.857 & 15.987 & -1.805 & 0.0711 \\
A9 & -15.078 & 8.609 & -1.752 & 0.0798 \\
\hline \multicolumn{5}{c}{ AIC 23.551. }
\end{tabular}

The A1 and A2 predictors, representative of the area of the lower crown layers, showed increases interpreted as an increase in lower crown cross-section width due to the bending of branches from upper crown layers. In contrast, the A5, A6, and A9 predictors showed a decrease caused by bending of the grown branches to the lower parts of the tree, decreasing the width of the crown at the respective heights. The initial Akaike Information Criteria (AIC) score was 29.639 and improved to 23.551 with the final GLM.

In the validation set, morphologic changes were manually detected in 14 trees. The model classified 19 trees into the morphologic change class; 12 (i.e., $86 \%$ of the real count) of them were classified correctly, and five represented the commission error (false positive). Datasets comparison is described in Table 3. 
Table 3. Explanation of calculated values for training and validation datasets. Trees-total number of trees in dataset; change-number of trees with branch bending detected; false negative- trees with branch bending but not detected; false positive-incorrectly detected as trees with branch bending; correct-correctly detected as trees with branch bending.

\begin{tabular}{cccccc}
\hline Dataset & Trees & Change & False Negative & False Positive & Correct \\
\hline Training & 204 & 29 & 1 & 2 & 28 \\
Validation & 204 & 14 & 2 & 5 & 12 \\
\hline
\end{tabular}

\section{Discussion}

The high detection rate was achieved mainly due to the limited stocking of the stand. This greatly limited the possibility of not detecting the actual tree because individual tree canopies were not often connecting, as is mentioned by [27]. The limitations of the IWS segmentation from ULS data in close canopy forest were tested and compared with several other methods by [15]. The study of [26] mentioned reaching high detection potential of individual standing trees. Moreover, there was no substantial undergrowth, except for some Norway spruce (Picea abies L.) in the understory that was shorter than the minim tree height threshold of $2 \mathrm{~m}$.

Estimated values of the derived GLM represent the movement of the points along the stem profile in the individual tree point clouds caused by the bending of branches to the lower parts of the tree. Whereas the A1 predictor displayed the highest point increment due to bending of branches from the area above to the space where there were few branches and mainly only the stem (i.e., the points representing the stem); the A2 predictor displayed a lower increment, but still significant for the detection of bending branches in dead trees. The A5 predictor estimated value shows the highest decrease in points to lower parts with also a significant positive increment in points from A6, another significant predictor. Logically, the A9 predictor showed a drop in points from the top part of the tree, where a positive change in cross-section area could not be expected.

In comparison to TLS methods, the ULS is a much less time-demanding method for data acquisition. One 21-min flight can be sufficient for data collection of a forest stand approximately 5 hectares in size; this is in contrast to TLS data acquisition of a comparable area, which may take several days to complete $[12,13]$. In the case of repeated ULS data acquisition, time required for flight preparation, as flight trajectory optimizing a planning, can be eliminated by using identical predefined trajectory, which was the case in this study. However, the presented methodology for temporal change detection does not require data acquired with flight with identical trajectories. Due to the high pulse frequency of the scanner and multiple returns from beams penetrating the canopy, point clouds of uniform densities of high-precision points are produced. The changes can be detected in the whole scanned area, regardless of the actual trajectory, if the trajectory parameters such as flight height and flight line spacing responsible for point cloud density and accuracy are kept constant. A standard method for the practical evaluation of current status of individual trees or stands is based on human observation while walking in the forest stands. However, this would be an incredibly time-demanding method for the detection of bending branches on individual trees.

Another mapping possibility is the use of the mobile laser scanning (MLS) method in such an open canopy stand. From the MLS point of view, there are GNSS accessibility options under the canopy, which could be limited in such a stand as was used for purposes of this study; however, this is only the case in trajectory-based solutions [42]. Within the simultaneous localization and mapping (SLAM) solutions that were used in the ULS and MLS methods compared for stem detection in the study of Hyppa [43], they may also include a possible trajectory-based solution for use under canopies with insufficient GNSS signal. The MLS method can possibly influence the quality of individual tree point clouds, mainly because of the point cloud density issues due to the necessity of observation of the whole tree profile. The trees in this study had branches very low on the stem, which may have 
possibly caused laser beam shading obstructions. However, the MLS data collection method for the phenomenon described in this study requires further research.

During the year, the morphological structure of the tree reacts to the circadian rhythm and the changing solar zenith angles. We offer several explanations of the dead branches' movements:

- In cases where portions of the roots are still alive, the existing root connection to neighboring living trees can mediate responses to environmental conditions, even in the case of fatal loss of assimilation apparatus. Fungal interconnections support not only the transfer of water [44] but also carbon and nitrogen compounds [45]. Moreover, mycorrhizal connections act as conduits for signaling between plants [46]. It is highly probable that these conduits can also transport signals associated with solar radiation. Water uptake is driven by the transpiration demands of the assimilation apparatus. In the case of dead trees, water uptake could be due to the transpiration apparatus of the living tree and/or water efflux through the lenticels in the periderm $[47,48]$. This hypothesis is supported by the close proximity of living blue spruce to all dead trees in the study.

- Water uptake from the soil by any surviving roots of the dead trees without any support from other trees or fungus. This hypothesis supports the highest amount of precipitation during the winter period, e.g., with a surplus of water during the early spring and autumn. The water uptake through root systems which have been killed was described by [49].

- The branch shifting during the year could be related to the branch length [50]. This observation using an RTM approach in a mixed broadleaf forest confirmed the sagging of a branch and on the opposite branch stub rising after losing its terminal part, simply as the total branch weight decreased.

While branch movement has been detected on live plants [51] or live trees $[52,53]$ and has been described by changes in turgor at the molecular level of plant or tree components, in this study, we detected branch movements of dead trees. In contrast, dead branch movement has been observed to be related to the decay process with the loss of branch terminals [50]. Excluding root interconnection between living and dead trees, dead branch movement is not a physiological process but physical one. Our multi-temporal data samples taken throughout one year provide evidence that the branches of dead trees are capable of returning to their original spring position in the fall after displaying drooping branches during the summer growth period. In contrast to our study, in which we used three scans throughout the year, Barak et al. [51] only used two time-distanced scans per tree; thus, we could determine if the branches returned to their "initial" position. The TLS method is, for this purpose, time-consuming, in contrast to the ULS method, which is adequate for the derivation of representative individual tree point clouds for many common forest inventory values, and its time efficiency compared to TLS methods makes it more practical for surveys across larger areas [12,13,15].

An important scientific question is how these bending branches trees could potentially influence results of the $\mathrm{ABA}$ and also the calculation of horizontal crown projections. For example, the relationship between crown size and $\mathrm{DBH}$, an important factor in forestry, was described by [5,54]. In large disturbances, such as recent extensive bark beetle outbreaks in Central Europe, AGB calculations may vary depending on the season of measurement. The points in the individual tree point cloud moved down along the stem profile, as calculated by a GLM, and the bending branches will produce smaller canopy projections. These canopy changes, similarly described by [9], can clearly influence the results of ABA, as highlighted in large disturbance areas with high numbers of dead trees, and the resultant statistical metrics, as presented in [2], may also vary. Carbon stock estimates based on CHM can also be influenced by detected changes in the calculated quantiles. These changes can influence results of some studies, such as $[29,30]$, based on their methods with regard to the current status of dead tree canopy changes in large bark beetle disturbance areas that are currently located throughout Central Europe. 


\section{Conclusions}

The ULS method proved to be adequate to detect an increase or loss at the tree component level based on a flight time series of a blue spruce stand. This study showed high spatial and temporal resolution of ULS with regard to tree branch movements of dead trees throughout the year based on time series of three flights. The detection of trees with bending branches was successful using a derived GLM, which was further tested using a validation dataset. These findings could have important implications for remote sampling of forested areas with large numbers of dead trees.

Author Contributions: Conceptualization, M.S. and P.S.; methodology, M.S., K.K. and P.S.; software, M.S., K.K. and P.S.; validation, M.S., K.K. and P.S.; formal analysis, M.S., K.K. and P.S.; investigation, M.S.; resources, P.S. and R.M.; data curation, M.S., K.K., P.S. and R.M.; writing-original draft preparation, M.S.; writing-review and editing, K.K., P.S. and I.T.; visualization, M.S.; supervision, P.S.; project administration, M.S. and P.S.; funding acquisition, P.S. and R.M. All authors have read and agreed to the published version of the manuscript.

Funding: This research was founded by “OP RDE, grant number CZ.02.1.01/0.0/0.0/15_003/0000433 (Building up an excellent scientific team and its spatiotechnical background focused on mitigation of the impact of climatic changes to forests from the level of a gene to the level of a landscape at the FFWS CZU Prague)" and "Ministry of Agriculture of the Czech Republic grant number QK1920458".

Conflicts of Interest: The authors declare no conflict of interest. The founders had no role in the design of the study; in the collection, analyses, or interpretation of data; in the writing of the manuscript, or on the decision to publish results.

\section{References}

1. Surovỳ, P.; Kuželka, K. Acquisition of forest attributes for decision support at the forest enterprise level using remote-sensing techniques-A review. Forests 2019, 10, 273. [CrossRef]

2. Næsset, E.; Gobakken, T. Estimating forest growth using canopy metrics derived from airborne laser scanner data. Remote Sens. Environ. 2005, 96, 453-465. [CrossRef]

3. Means, J.E.; Acker, S.A.; Fitt, B.J.; Renslow, M.; Emerson, L.; Hendrix, C.J. Predicting forest stand characteristics with airborne scanning lidar. Photogramm. Eng. Remote Sens. 2000, 66, 1367-1371.

4. Packalen, P.; Strunk, J.; Packalen, T.; Maltamo, M.; Mehtätalo, L. Resolution dependence in an area-based approach to forest inventory with airborne laser scanning. Remote Sens. Environ. 2019, 224, $192-201$. [CrossRef]

5. Verma, N.K.; Lamb, D.W.; Reid, N.; Wilson, B. An allometric model for estimating DBH of isolated and clustered Eucalyptus trees from measurements of crown projection area. For. Ecol. Manag. 2014, 326, 125-132. [CrossRef]

6. Darwin, C. The Power of Movement in Plants; Appleton: New York, NY, USA, 1897.

7. McClung, C.R. The plant circadian oscillator. Biology 2019, 8, 14. [CrossRef]

8. Zobel, B.J.; Jett, J.B. Genetics of Wood Production; Springer Science \& Business Media: Cham, Switzerland, 2012; ISBN 3642795145.

9. Pokorny, R.; Tomaskova, I.; Marek, M.V. The effects of elevated atmospheric [CO2] on Norway spruce needle parameters. Acta Physiol. Plant. 2011, 33, 2269-2277. [CrossRef]

10. Puttonen, E.; Briese, C.; Mandlburger, G.; Wieser, M.; Pfennigbauer, M.; Zlinszky, A.; Pfeifer, N. Quantification of overnight movement of birch (Betula pendula) branches and foliage with short interval terrestrial laser scanning. Front. Plant Sci. 2016, 7, 222. [CrossRef]

11. Zlinszky, A.; Molnár, B.; Barfod, A.S. Not all trees sleep the same-High temporal resolution terrestrial laser scanning shows differences in nocturnal plant movement. Front. Plant Sci. 2017, 8, 8. [CrossRef]

12. Brede, B.; Lau, A.; Bartholomeus, H.M.; Kooistra, L. Comparing RIEGL RiCOPTER UAV LiDAR derived canopy height and DBH with terrestrial LiDAR. Sensors 2017, 17, 2371. [CrossRef]

13. Wieser, M.; Mandlburger, G.; Hollaus, M.; Otepka, J.; Glira, P.; Pfeifer, N. A case study of UAS borne laser scanning for measurement of tree stem diameter. Remote Sens. 2017, 9, 1154. [CrossRef]

14. Liu, K.; Shen, X.; Cao, L.; Wang, G.; Cao, F. Estimating forest structural attributes using UAV-LiDAR data in Ginkgo plantations. ISPRS J. Photogramm. Remote Sens. 2018, 146, 465-482. [CrossRef] 
15. Peng, X.; Li, X.; Wang, C.; Zhu, J.; Liang, L.; Fu, H.; Du, Y.; Yang, Z.; Xie, Q. SPICE-based SAR tomography over forest areas using a small number of P-band airborne F-SAR images characterized by non-uniformly distributed baselines. Remote Sens. 2019, 11, 975. [CrossRef]

16. Wang, Y.; Lehtomäki, M.; Liang, X.; Pyörälä, J.; Kukko, A.; Jaakkola, A.; Liu, J.; Feng, Z.; Chen, R.; Hyyppä, J. Is field-measured tree height as reliable as believed-A comparison study of tree height estimates from field measurement, airborne laser scanning and terrestrial laser scanning in a boreal forest. ISPRS J. Photogramm. Remote Sens. 2019, 147, 132-145. [CrossRef]

17. Jurjević, L.; Liang, X.; Gašparović, M.; Balenović, I. Is field-measured tree height as reliable as believed-Part II, A comparison study of tree height estimates from conventional field measurement and low-cost close-range remote sensing in a deciduous forest. ISPRS J. Photogramm. Remote Sens. 2020, 169, 227-241. [CrossRef]

18. Lefsky, M.; Harding, D.; Blair, J.; Parker, G. Laser altimeter canopy height profiles: Methods and validation for closed-canopy, broadleaf forests. Remote Sens. Environ. 2001, 76, 283-297.

19. Næsset, E.; Gobakken, T. Estimation of above- and below-ground biomass across regions of the boreal forest zone using airborne laser. Remote Sens. Environ. 2008, 112, 3079-3090. [CrossRef]

20. Solodukhin, V.I.; Zhukov, A.Y.; Mazhugin, I.N.; Narkevich, V.I. Metody Izuchenija Vertikal'nyh Sechenij Drevostoev (Method of Study of Vertical Sections of Forest Stands); Leningrad Scientific Research Institute of Forestry: Leningrad, Russia, 1976; 55p.

21. Nelson, R.; Krabill, W.; MacLean, G. Determining forest canopy characteristics using airborne laser data. Remote Sens. Environ. 1984, 15, 201-212. [CrossRef]

22. Rosati, A.; Paoletti, A.; Caporali, S.; Perri, E. The role of tree architecture in super high density olive orchards. Sci. Hortic. 2013, 161, 24-29. [CrossRef]

23. Lau, A.; Bentley, L.P.; Martius, C.; Shenkin, A.; Bartholomeus, H.; Raumonen, P.; Malhi, Y.; Jackson, T.; Herold, M. Quantifying branch architecture of tropical trees using terrestrial LiDAR and 3D modelling. Trees Struct. Funct. 2018, 32, 1219-1231. [CrossRef]

24. Gonzalez de Tanago, J.; Lau, A.; Bartholomeus, H.; Herold, M.; Avitabile, V.; Raumonen, P.; Martius, C.; Goodman, R.C.; Disney, M.; Manuri, S.; et al. Estimation of above-ground biomass of large tropical trees with terrestrial LiDAR. Methods Ecol. Evol. 2018, 9, 223-234. [CrossRef]

25. Jaakkola, A.; Hyyppä, J.; Kukko, A.; Yu, X.; Kaartinen, H.; Lehtomäki, M.; Lin, Y. A low-cost multi-sensoral mobile mapping system and its feasibility for tree measurements. ISPRS J. Photogramm. Remote Sens. 2010, 65, 514-522. [CrossRef]

26. Wallace, L.; Lucieer, A.; Watson, C.; Turner, D. Development of a UAV-LiDAR system with application to forest inventory. Remote Sens. 2012, 4, 1519-1543. [CrossRef]

27. Panagiotidis, D.; Abdollahnejad, A.; Surový, P.; Chiteculo, V. Determining tree height and crown diameter from high-resolution UAV imagery. Int. J. Remote Sens. 2017, 38, 2392-2410. [CrossRef]

28. Lowe, D.G. Method and Apparatus for Identifying Scale Invariant Features in an Image. U.S. Patent US6711293B1, 23 March 2004.

29. Lee, S.K.; Fatoyinbo, T.; Qi, W.; Hancock, S.; Armston, J.; Dubayah, R. GEDI and TanDEM-X fusion for 3D forest structure parameter retrieval. Int. Geosci. Remote Sens. Symp. 2018, 2018, 380-382.

30. Qi, W.; Dubayah, R.O. Combining Tandem-X InSAR and simulated GEDI lidar observations for forest structure mapping. Remote Sens. Environ. 2016, 187, 253-266. [CrossRef]

31. Mitchard, E.T.A. The tropical forest carbon cycle and climate change. Nature 2018, 559, 527-534. [CrossRef]

32. Baccini, A.; Walker, W.; Carvalho, L.; Farina, M.; Houghton, R.A. Response to Comment on “Tropical forests are a net carbon source based on aboveground measurements of gain and loss". Science 2019, 363, 230-234. [CrossRef]

33. Breiman, L. Random forests. Mach. Learn. 2001, 45, 5-32. [CrossRef]

34. Šrámek, V.; Slodičák, M.; Lomský, B.; Balcar, V.; Kulhavý, J.; Hadaš, P.; Pulkráb, K.; Šišák, L.; Pěnička, L.; Sloup, M. The Ore Mountains: Will Successive Recovery of Forests from Lethal Disease Be Successful. Mt. Res. Dev. 2008, 28, 216-221. [CrossRef]

35. Černý, K.; Pešková, V.; Soukup, F.; Havrdová, L.; Strnadová, V.; Zahradník, D.; Hrabětová, M. Gemmamyces bud blight of Picea pungens: A sudden disease outbreak in Central Europe. Plant Pathol. 2016, 65, 1267-1278. [CrossRef]

36. Riegl. RIEGL VUX-SYS. 2019, Volume 4. Available online: http://www.riegl.com/uploads/tx_pxpriegldownloads/ RIEGL_VUX-SYS_Datasheet_2020-10-02_01.pdf (accessed on 20 November 2020). 
37. Czech Republic. Letecký Předpis L 2 Pravidla Létání. 2014. Available online: https://aim.rlp.cz/predpisy/ predpisy/dokumenty/L/L-2/data/print/L-2_cely.pdf (accessed on 20 November 2020).

38. Westoby, M.J.; Brasington, J.; Glasser, N.F.; Hambrey, M.J.; Reynolds, J.M. "Structure-from-Motion" photogrammetry: A low-cost, effective tool for geoscience applications. Geomorphology 2012, 179, 300-314. [CrossRef]

39. Lisein, J.; Pierrot-Deseilligny, M.; Bonnet, S.; Lejeune, P. A photogrammetric workflow for the creation of a forest canopy height model from small unmanned aerial system imagery. Forests 2013, 4, 922-944. [CrossRef]

40. Bosshard, W.; Müller, E. Kronenbilder: Mit Nadel-und Blattverlustprozenten; Eidgenössische Anstalt für das Forstliche Versuchswesen: Birmensdorf, Switzerland, 1986.

41. Pekár, S.; Brabec, M. Modern Analysis of Biological Data: Generalized Linear Models in R; Masarykova Univerzita: Brno, Czech Republic, 2016; ISBN 8021081066.

42. Hyyppä, E.; Hyyppä, J.; Hakala, T.; Kukko, A.; Wulder, M.A.; White, J.C.; Pyörälä, J.; Yu, X.; Wang, Y.; Virtanen, J.P.; et al. Under-canopy UAV laser scanning for accurate forest field measurements. ISPRS J. Photogramm. Remote Sens. 2020, 164, 41-60. [CrossRef]

43. Hyyppä, E.; Yu, X.; Kaartinen, H.; Hakala, T.; Kukko, A.; Vastaranta, M.; Hyyppä, J. Comparison of Backpack, Handheld, Under-Canopy UAV, and Above-Canopy UAV Laser Scanning for Field Reference Data Collection in Boreal Forests. Remote Sens. 2020, 12, 3327. [CrossRef]

44. Plamboeck, A.H.; Dawson, T.E.; Egerton-Warburton, L.M.; North, M.; Bruns, T.D.; Querejeta, J.I. Water transfer via ectomycorrhizal fungal hyphae to conifer seedlings. Mycorrhiza 2007, 17, 439-447. [CrossRef] [PubMed]

45. Teste, F.P.; Simard, S.W.; Durall, D.M. Role of mycorrhizal networks and tree proximity in ectomycorrhizal colonization of planted seedlings. Fungal Ecol. 2009, 2, 21-30. [CrossRef]

46. Babikova, Z.; Gilbert, L.; Bruce, T.J.A.; Birkett, M.; Caulfield, J.C.; Woodcock, C.; Pickett, J.A.; Johnson, D. Underground signals carried through common mycelial networks warn neighbouring plants of aphid attack. Ecol. Lett. 2013, 16, 835-843. [CrossRef]

47. Baret, M.; DesRochers, A. Root connections can trigger physiological responses to defoliation in nondefoliated aspen suckers. Botany 2011, 89, 753-761. [CrossRef]

48. Simard, S.W.; Jones, M.D.; Durall, D.M. Carbon and nutrient fluxes within and between mycorrhizal plants. In Mycorrhizal Ecology; Springer: Cham, Switzerland, 2003; pp. 33-74.

49. Kramer, P.J. The intake of water through dead root systems and its relation to the problem of absorption by transpiring plants. Am. J. Bot. 1933, 20, 481-492. [CrossRef]

50. Putman, E.B.; Popescu, S.C.; Eriksson, M.; Zhou, T.; Klockow, P.; Vogel, J.; Moore, G.W. Detecting and quantifying standing dead tree structural loss with reconstructed tree models using voxelized terrestrial lidar data. Remote Sens. Environ. 2018, 209, 52-65. [CrossRef]

51. Barak, S.; Tobin, E.M.; Green, R.M.; Andronis, C.; Sugano, S. All in good time: The Arabidopsis circadian clock. Trends Plant Sci. 2000, 5, 517-522. [CrossRef]

52. Ibañez, C.; Ramos, A.; Acebo, P.; Contreras, A.; Casado, R.; Allona, I.; Aragoncillo, C. Overall Alteration of Circadian Clock Gene Expression in the Chestnut Cold Response. PLoS ONE 2008, 3, e3567. [CrossRef] [PubMed]

53. Solomon, O.L.; Berger, D.K.; Myburg, A.A. Diurnal and circadian patterns of gene expression in the developing xylem of Eucalyptus trees. S. Afr. J. Bot. 2010, 76, 425-439. [CrossRef]

54. Shimano, K. Analysis of the relationship between DBH and crown projection area using a new model. J. For. Res. 1997, 2, 237-242. [CrossRef]

Publisher's Note: MDPI stays neutral with regard to jurisdictional claims in published maps and institutional affiliations.

(C) 2020 by the authors. Licensee MDPI, Basel, Switzerland. This article is an open access article distributed under the terms and conditions of the Creative Commons Attribution (CC BY) license (http://creativecommons.org/licenses/by/4.0/). 